\title{
Que geometria ensinar? Uma breve história da redefinição do conhecimento elementar matemático para crianças
}

\author{
Wagner Rodrigues Valente*
}

\begin{abstract}
Resumo
0 artigo aborda a geometria para crianças, seu ensino para alunos das primeiras séries escolares. Leva em conta, inicialmente, a trajetória da Geometria para o nível elementar, desde, praticamente, a Independência do Brasil. Nessa análise, evidencia a permanência de conteúdos da geometria euclidiana até quase meados do século XX. Em seguida, analisa as propostas de alteração do ensino de Geometria elaboradas na década de 1960. Com isso, procura mostrar as intenções de modificar os conteúdos desse ramo matemático, em busca da redefinição de um novo elementar: um novo conhecimento elementar de geometria, vindo de processos de apropriação das contribuições trazidas pelos estudos da Psicologia cognitiva.

Palavras-chave

Educação Matemática; ensino primário; geometria; história da Educação Matemática.
\end{abstract}

* Professor Adjunto LivreDocente do Departamento de Educação da Escola de Filosofia, Letras e Ciências Humanas e Coordenador do Grupo de Pesquisa de História da Educação Matemática (www.unifesp. $\mathrm{br} /$ centros/ghemat) da Universidade Federal de São Paulo, Brasil. wagner. valente@unifesp.br 


\title{
Which geometry should we teach? A brief history of the redefinition of elementary mathematics knowledge for children
}

\begin{abstract}
The article discusses geometry for children and its teaching for students from early grades. It takes into account, firstly, the geometry journey at the elementary level since practically the Independence of Brazil. This analysis highlights the presence of Euclidean geometry contents up to the mid-twentieth century. It then analyzes the proposed amendment to the teaching of geometry developed in the 1960s. Thus, this article attempts to show the intentions to modify the contents of this branch of mathematics in search of a redefinition of the 'new elementary': a new elementary knowledge of geometry, coming from the appropriation processes of the contributions made by studies of cognitive psychology.
\end{abstract}

Key words mathematics education; primary education; geometry; history of mathematics education. 


\section{Preliminares}

Ao que parece, os movimentos pedagógicos têm como característica marcante a metodologia do ensino. Explicando melhor: a chegada de uma nova corrente pedagógica se dá, sobretudo, por propostas diferentes de ensinar a crianças e adolescentes as matérias escolares. Assim, o ensino tradicional embate-se com a proposta de um ensino mais ativo. 0 ensino intuitivo trava batalha com o estudo de memória, dos processos que levam os alunos a decorarem as lições. O que fica conhecido na história da educação matemática como Movimento da Matemática Moderna - MMM - também coloca em cena o debate das metodologias, dos modos de tratar os temas escolares. $E$, neste ponto, sem muito discorrer sobre o $M M M$, cabe anotar que, sobretudo, entre as décadas de 1960-1980, através de um movimento internacional, pretende-se alterar o ensino de matemática nos níveis elementares. Busca-se uma aproximação maior entre o nível superior de ensino e aquele ministrado no curso secundário e, também, no primário ${ }^{1}$. A esse tempo, é voz comum a divulgação da perfeita articulação entre os avanços da Psicologia cognitiva (Jean Piaget) e a Matemática organizada através das estruturas algébricas (Grupo Bourbaki²). 0 período, na Educação Matemática, tem como ícone a inclusão da Teoria dos Conjuntos no currículo escolar.

Mas, para além das discussões metodológicas, o MMM faz surgir algo um tanto incomum, diante daquilo que caracteriza os movimentos pedagógicos. O Movimento trata de redefinir o que até então se considerava elementar para o ensino de Matemática. Isso significa uma intervenção direta sobre os conteúdos a ensinar.

Este texto aborda a Geometria para crianças. Considera que o exemplo das propostas de alteração do ensino de Geometria é revelador das intenções de modificar os conteúdos desse tema matemático, em busca da redefinição de um novo elementar. Além disso, o estudo analisa o modo de apropriação da proposta modernista para o ensino de Geometria nas séries iniciais.

\section{História cultural da}

\section{Educação Matemática:} régua, compasso, esquadro...

Em A história cultural - entre práticas e representações, uma de suas obras - talvez das mais conhecidas e utilizadas por pesquisadores da história da educação no Brasil -, Roger Chartier,
1. Na organização escolar brasileira, os termos "ensino primário" e "ensino secundário" são utilizados no período que antecede a Lei de Diretrizes e Bases da Educação, de 1971. 0 primeiro, correspondendo, em geral, às quatro primeiras séries escolares; o segundo, aos anos de ensino que antecedem o nível universitário (hoje compreendendo o Ensino Fundamental II e o Ensino Médio).

2. Grupo Bourbaki refere-se ao nome de um grupo de matemáticos, formado em meados dos anos 1930, na França. No entender desse Grupo, deve-se conceber a Matemática a partir de sua unidade, do método axiomático e do conceito de estrutura. 
desde o título, parece já tentar esclarecer do que trata o ofício do historiador cultural: será ele um trabalho que se situa "entre práticas e representações". Para chegar a essa síntese, Chartier irá, paulatinamente, levar o leitor de considerações amplas sobre a história e a sua transformação ao longo dos últimos tempos, aos conceitos e às ferramentas intelectuais necessários ao entendimento da problemática do "mundo como representação". Assim é que na "Introdução" de sua obra, Chartier (1990, p. 16-17) menciona como pensa a história cultural: "A história cultural, tal como a entendemos, tem por principal objeto identificar o modo como em diferentes lugares e momentos uma determinada realidade social é construída, pensada, dada a ler".

E como a realidade social é construída, pensada, dada a ler? Chartier vai desenvolver nesse texto uma categoria fundamental para essa análise. Trata-se do conceito de representação. A elaboração desse conceito passa inicialmente por aquilo que ele não é. Pela contraposição àquilo que já estava posto numa historiografia anterior àquela da história cultural. Assim, o conceito de representação supera os debates historiográficos que contrapunham a

objetividade das estruturas (que seria o terreno da história mais segura, aquela que, manuseando documentos seriados, quantificáveis, reconstrói as sociedades tais como eram na verdade) e a subjetividade das representações (a que estaria ligada uma outra história, dirigida às ilusões de discursos distanciados do real). Tal clivagem atravessou profundamente a história, mas também outras ciências sociais, como a sociologia ou a etnologia, opondo abordagens estruturalistas e perspectivas fenomenológicas, trabalhando as primeiras em grande escala sobre as posições e relações dos diferentes grupos, muitas vezes identificados com classes, e privilegiando as segundas o estudo dos valores e dos comportamentos de comunidades mais restritas, frequentemente consideradas homogêneas. (Chartier, 1990, p. 18).

Superar a história estruturalista parece, hoje, algo já consolidado. Todo o movimento que toma conta dos diferentes saberes durante décadas no século XX, inclusive da Matemática, entra em refluxo nas décadas finais do século passado. Talvez 0 que deva ficar mais nítido seja a superação da outra vertente que se confronta com o estruturalismo a partir do que Chartier chama de "subjetividade das representações”. Ultrapassar o modo de pensar nas representações como esquemas psicológi- 
cos, subjetivos, sejam eles coletivos ou individuais, vai levar o autor a dedicar muitas páginas em sua obra.

Mas, então, o que é representação? Chartier, em alusão à ultrapassagem do caráter de subjetividade que, a princípio, poder-se-ia atribuir ao conceito, dá-lhe outra substância, ao afirmar que,

mais do que o conceito de mentalidade, ela (a noção de representação) permite articular três modalidades da relação com o mundo social: em primeiro lugar, o trabalho de classificação e de delimitação que produz as configurações intelectuais múltiplas, através das quais a realidade é contraditoriamente construída pelos diferentes grupos; seguidamente, as práticas que visam fazer reconhecer uma identidade social, exibir uma maneira própria de estar no mundo, significar simbolicamente um estatuto e uma posição; por fim, as formas institucionalizadas e objetivadas graças às quais uns "representantes" (instâncias coletivas ou pessoas singulares) marcam de forma visível e perpetuada a existência do grupo, da classe ou da comunidade. (Chartier, 1990, p. 23, grifo nosso).

Pensar assim a relação com o mundo social, isto é, através das representações, coloca em cena, de acordo com Chartier, a discussão sobre como lidamos com elas. Se, ao nos relacionarmos com a realidade, fazemos isso através das representações, como operamos com elas? Como fazemos uso delas?

Para responder a tais questões, Chartier traz a seu trabalho o que alicerçou empiricamente às suas investigações: os estudos históricos sobre o livro e a leitura:

A problemática do "mundo como representação", moldado através das séries de discursos que o apreendem e o estruturam, conduz obrigatoriamente a uma reflexão sobre o modo como uma figuração desse tipo pode ser apropriada pelos leitores dos textos (ou das imagens) que dão a ver e a pensar o real. Daí, neste livro e noutros, mais especificamente consagrados às práticas de leitura, o interesse manifestado pelo processo por intermédio do qual é historicamente produzido um sentido e diferenciadamente construída uma significação. (Chartier, 1990, p. 24, grifo nosso). 
A preocupação com a recepção e com o uso das representações levou o autor a lançar mão de outro conceito-chave para seu arcabouço teórico: o conceito de apropriação. Através dessa categoria teórica, será dada a possibilidade de compreender como ocorrem os processos criativos de consumo das representações. Esse conceito é considerado por Chartier do seguinte modo:

A apropriação, tal como a entendemos, tem por objetivo uma história social das interpretações, remetidas para as suas determinações fundamentais (que são sociais, institucionais, culturais) e inscritas nas práticas específicas que as produzem. (Chartier, 1990, p. 26).

Assim, os conceitos de representação, prática e apropriação constituirão, para Chartier, os elementos fundamentais dos estudos que pretendem tratar de uma história cultural.

Feita essa visita rapidíssima aos estudos de Chartier, convém repor a discussão em termos do título deste item: "História cultural da Educação Matemática: régua, compasso, esquadro...". Desse modo, mesmo correndo sério risco de simplificar em demasia assunto tão complexo, cabe a interrogação do que deveria tratar uma tal "história cultural da educação matemática". Quais seriam os seus instrumentos de trabalho, as suas ferramentas conceituais, a sua régua, o seu compasso e o seu esquadro? Que perguntas eles poderiam ajudar a formular? Como resposta, poder-se-ia dizer que os estudos históricos culturais da Educação Matemática deveriam caracterizar-se pelas pesquisas que intentam saber como, historicamente, foram construídas representações sobre os processos de ensino e aprendizagem da Matemática e de que modo essas representações passaram a ter um significado nas práticas pedagógicas dos professores, em seus mais diversos contextos e épocas. E, aqui, importa retomar o tema deste texto, tornando mais precisa a sua interrogação principal: Como ocorre a proposta de modificação dos conteúdos de Geometria a ensinar nas séries iniciais e de que modo as obras didáticas lhe dão significado?

\section{A geometria de sempre: a geometria euclidiana}

Sem tratar extensivamente do termo "elementar", o que poderia conduzir aos antigos, fique-se com a noção dada pelo Novo Dicionário do Aurélio: "referente às primeiras noções de uma arte ou ciência”. Assim é: para os anos iniciais da esco- 
la, devem ser ensinados os rudimentos, o que é primário, as primeiras noções de uma ciência, as primeiras noções da geometria, a geometria elementar. E ela é, desde longuíssima data, a geometria euclidiana. Mas é necessário precisar o que se entende por geometria euclidiana. E, neste ponto, o tema envolve dificuldades. Ao que parece, de acordo com o nível de conceituação, há uma determinada caracterização desse ramo do saber matemático. Por exemplo, o matemático Felix Klein (1849-1925) define a geometria euclidiana como aquela que estuda as propriedades das figuras que permanecem invariantes quando os elementos destas são submetidos a transformações isométricas (rotações, translações, reflexões em retas e suas composições). Grosso modo, isso significa dizer que, para Klein, a geometria euclidiana estuda somente figuras congruentes entre si. Essa definição omite o estudo das figuras semelhantes. No entanto, a geometria de Euclides aborda não apenas o estudo de figuras congruentes, mas também o estudo de figuras semelhantes. Veja-se o Livro VI, de Euclides. A geometria euclidiana pode também ser caracterizada de outra forma: por um sistema de axiomas (de Hilbert, Birkhoff, Pogorelov ou de outros). Hilbert, por exemplo, caracteriza a geometria euclidiana por cinco grupos de axiomas: axiomas de incidência, axiomas de ordem, axiomas de congruência, axiomas de continuidade e axioma das paralelas. (Na geometria de Hilbert não há nenhum apelo à intuição e a figuras).

Para além da caracterização matemática propriamente dita - que, como se vê, difere, a depender da época e da base de conceituação -, este estudo interessa-se pela geometria euclidiana ensinada nas séries iniciais, nos primeiros anos escolares. Assim, uma forma de caracterizar essa geometria é considerá-la do mesmo modo que aqueles que intentam substituí-la por outros conteúdos, por outra geometria, mudando o saber elementar geométrico nas séries iniciais. Essa intenção ocorre explicitamente na vigência do Movimento da Matemática Moderna.

A geometria euclidiana a ser ensinada no curso primário - que nos textos oficiais é tratada por "geometria elementar" - é objeto de discussão nas propostas educacionais desde a Independência do Brasil:

0 ano de 1827 é o ano da Lei de 15 de novembro que cria escolas primárias a partir da Carta outorgada por D. Pedro I, em 1824, que estabelecia, dentre outras coisas, a gratuidade do ensino primário. 0 projeto da lei previa que "os professores ensinarão a ler, escrever e contar [...]". Os debates na 
Câmara modificaram o texto original e muita polêmica ocorreu a partir da sugestão de que fosse, no ensino primário, ensinada a "resolução prática dos problemas de geometria elementar" (Valente, 2007, p. 111, grifo nosso)

Ao que tudo indica, demorará algum tempo até que se estabilizem os conteúdos geométricos como um saber a ser ensinado no curso primário. Nas últimas décadas do século XIX, surgem obras que irão transformar-se em referências nacionais para o ensino primário, passando a incluir a geometria euclidiana para as séries iniciais.

Por essa época, muitas das aritméticas para as primeiras letras trazem, ao final, os rudimentos do que os alunos deveriam saber de geometria. Um exemplo importante é o de Souza Lobo, com sua Primeira Arithmetica para meninos. A obra alcança dezenas e dezenas de edições³. Seu texto sai à luz em 1874, atravessa o século XIX e chega às primeiras décadas do século passado.

A propósito de Souza Lobo, o pesquisador Luiz Carlos Pais considera que a rede de sociabilidade em que esse autor está envolvido em muito contribui para o sucesso de suas obras didáticas. Ela pode ser lida em traços de sua biografia: José Theodoro de Souza Lobo nasce em Porto Alegre, em sete de janeiro de 1846 e falece na mesma cidade, em nove de agosto de 1913. Atua como professor de Matemática da Escola Normal de Porto Alegre, escritor de obras literárias, inspetor da Instrução Pública e também proprietário de um colégio. Estuda na Escola Central do Rio de Janeiro, instituição que precede a criação da Escola Politécnica, onde Souza Lobo recebe o diploma de engenheiro geógrafo. Seus interesses intelectuais não estão restritos ao campo das ciências exatas. Desde os seus tempos de estudante, envolve-se em atividades literárias, escreve artigos para revistas e participa de projetos culturais em parceria com outros intelectuais gaúchos. É membro da Academia Rio-grandense de Letras e colaborador da revista Partenon Literário, onde publica artigos em 1869 (Pais, 2011, no prelo).

Em sua Primeira Arithmetica para meninos, Souza Lobo destina o último capítulo às “Definições de Geometria”. Nele estão a caracterização de “ponto”, “reta”, “ângulos", "triângulos", "quadriláteros" e o estudo breve das figuras geométricas.

Junto com os livros de aritmética, que têm, em seu final, noções de geome-

3. Pfromm Neto (1974, p. 76) informa que "em menos de nove anos, a Primeira Aritmética para meninos completou noveedições, totalizand0400.000 exemplaresimpressos". tria, há outro conjunto de obras, igualmente destinadas às séries iniciais da escola primária, que contêm somente geometria. Dois autores 
podem ser considerados best-sellers dessa produção didática. 0 primeiro deles, Abílio Borges.

Abílio Cesar Borges (1824-1891) nasce na Bahia e, em 1858, troca sua carreira de médico pela atividade educacional, ao fundar, nesse ano, o Ginásio Baiano; em 1871, transfere-se para o Rio de Janeiro, onde instala o Colégio Abílio. Em 1881, ganha de D. Pedro II o título de Barão de Macaúbas. Sobre esse personagem, há muitos estudos. Um deles, de autoria de Gondra e Sampaio (2010, p. 75), resume do seguinte modo sua trajetória:

Médico, gestor da instrução pública, dono de escola, homem de imprensa, autor de livros de destinação escolar, viajante, conselheiro da instrução, Dr. Abílio César Borges protagonizou algumas iniciativas na esfera pública e privada, como forma de demonstrar princípios educativos que abraçara no que se refere aos métodos de ensino, aprendizagem da leitura e escrita, aritmética e geometria, educação infantil e castigos corporais, por exemplo.

Da produção didática de Borges, no que interessa a este estudo, cabe destacar o livro Desenho linear ou elementos de Geometria prática popular, de 1878. A obra

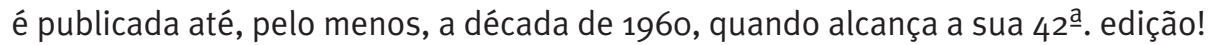

No livro de Borges, a geometria apresenta-se em onze capítulos que abordam, respectivamente: noções preliminares; do ponto e das linhas; posições de duas linhas retas e curvas; posição relativa das linhas; dos ângulos; dos polígonos; dos triângulos; dos quadriláteros; das figuras formadas por linhas curvas; dos sólidos; dos poliedros; dos sólidos redondos.

Primeiras noções de Geometria pratica, de Olavo Freire, publicado em 1894, é outro ícone da organização da geometria euclidiana para ser ensinada no curso primário. Assim como o livro do Barão de Macaúbas, tem publicação até meados do século XX. De seu autor, Olavo Freire (1869-1941), diferentemente de Abílio Borges e Souza Lobo, pouco se sabe. Professor carioca, é considerado um dos autores de livros didáticos que contribui para a pujança da Editora Francisco Alves. Tendo iniciado suas publicações na Editora Garnier, a partir de 1892, junto com outros nomes de sucesso, transfere-se para a Francisco Alves, levando consigo dez títulos que já havia publicado (Razzini, 2007, p. 31).

Das Primeiras noções de Geometria pratica, de Olavo Freire (1907), é possível dizer que: 
Trata-se de um livro de dimensão de $18 \mathrm{~cm}$ por $11 \mathrm{~cm}$, de capa dura, com 226 páginas, que incluem 490 exercícios, 92 problemas resolvidos e 381 gravuras, informações essas destacadas na capa do livro. Há ainda na capa, ao final, a frase "Approvada e premiada pelo Conselho de Instrucção Pública Federal". A geometria é distribuída em vinte e um capítulos, sendo os treze primeiros destinados ao estudo da geometria plana, finalizando com o cálculo de áreas de polígonos. 0s demais capítulos, reservados para a geometria espacial, incluem também o cálculo de áreas e volumes dos poliedros e corpos redondos (Leme da Silva, 2010, p. 6).

Souza Lobo, Abílio Borges e Olavo Freire podem ser considerados representantes de tantos outros autores que trazem para o nível mais elementar os conteúdos de Geometria que devem ser ensinados na escola de primeiras letras. Dezenas - talvez mais precisamente coubesse dizer centenas - de livros didáticos contendo Geometria para o ensino primário compõem o repertório de obras destinadas à escola primária, publicadas desde o século XIX. A geometria a ser ensinada para as classes iniciais é sempre a geometria euclidiana, a geometria de sempre. Os rudimentos, os elementos dos Elementos de Euclides são seus objetos de ensino. As mais simples figuras geométricas e suas propriedades constam como conteúdos elementares em todas as obras didáticas.

A despeito dos métodos, do modo como deve ser ensinada a Geometria para os primeiros passos escolares, que, a partir principalmente do final do século XIX, volta a atenção para as lições de coisas, para o método intuitivo, seguido das

4. Tome-se, do educador Lourenço Filho, um dos ícones da Escola Nova no Brasil, uma síntese do ideário escolanovista: "Do começo deste século para cá, essa concepção [a do ensino intuitivo] tende a ser substituída por outra, a de uma filosofia pragmatista (a verdade é utilidade), e de uma filosofia vitalista (além das impressões sensoriais há um quid, em cada indivíduo, que plasma as ideias a sua feição). 0 próprio pensamento para essa escola é ação: ação reduzida, mas ação. Ação reduzida e sistematizada pela linguagem, mas atividade. Daí, como consequência, não se pretender ensinar mais tão somente pela ação das coisas, mas pela ação do indivíduo, único capaz de organizar 0 espírito solidamente, para o seu fim normal: dirigir a ação" (Lourenço Filho apud Carvalho, 2002, p. 385-386). iniciativas da Escola Nova ${ }^{4}$, os conteúdos são sempre os rudimentos da geometria euclidiana.

Tudo parece mudar nessa estabilidade de conteúdos a ensinar em geometria, com a divulgação dos estudos de Jean Piaget. Entra em discussão, a partir das pesquisas do epistemólogo suíço, um novo elementar. A geometria euclidiana não mais deve ser considerada como conteúdo matemático dos primeiros passos escolares. 


\title{
Piaget e o ensino de geometria
}

Dentre as dezenas de obras publicadas por Jean Piaget, figura a de 1947, intitulada La Représentation de l'Espace chez l'Enfant's. No Prólogo da obra, menciona-se que

\begin{abstract}
os tratados elementares da geometria são mais ou menos unânimes em nos apresentar as noções espaciais iniciais como repousando em intuições euclidianas: retas, ângulos, quadrados e círculos, medidas etc. Esta opinião parece, aliás, confirmada pelo estudo da percepção e das "boas formas" visuais ou táteis. Mas, por outro lado, a análise abstrata das geometrias tende a demonstrar que as noções espaciais fundamentais não são euclidianas: são "topológicas", isto é, repousam simplesmente nas correspondências qualitativas bicontínuas que recorrem aos conceitos de vizinhança e de separação, de envolvimento e de ordem etc., mas ignoram qualquer conservação das distâncias, assim como toda projetividade. Ora, nós constataremos precisa e incessantemente que o espaço infantil, cuja natureza essencial é ativa e operatória, começa por intuições topológicas elementares, bem antes de tornar-se simultaneamente projetivo e euclidiano (Piaget; Inhelder, 1993, p. 12).
\end{abstract}

No mesmo Prólogo, um pouco mais adiante, Piaget e Inhelder postam a tese da obra de que a criança passa primeiro pelo estágio topológico, antes do euclidiano, na apropriação do espaço. Os autores inferem como deveria ser o ensino de geometria para crianças:

0 ensino da geometria poderia ganhar muito ao adaptar-se à evolução espontânea das noções, ainda que - acabamos de pressenti-lo - tal evolução seja muito mais próxima da construção matemática do que o são a maioria dos manuais ditos "elementares". Tem sido dito que a "teoria dos conjuntos" de Cantor deveria ser ensinada na escola primária. Nós não estaríamos longe de pensar o mesmo no que se refere aos elementos da topologia... (Piaget; Inhelder, 1993, p. 12, grifos nossos).

5. 0 texto é traduzido para o português, em 1993, pela psicóloga Bernardina Machado de Albuquerque e publicado pela Editora Artes Médicas. Seu título, em português, passa a ser $A$ representação do espaço na criança. Para manter a precisão, é preciso mencionar que Piaget, no livro, faz parceria com Bärbel Inhelder. 
Assim, desde o Prólogo da obra, Piaget e Inhelder fazem apelo, em realidade, a uma mudança no que deveria ser elementar no ensino de Geometria para crianças. Dever-se-ia abandonar a milenar ideia do ensino dos rudimentos dos Elementos de Euclides, voltando-se a atenção para os elementos da Topologia. Não irá demorar muito para que o apelo faça eco, ganhe o debate pedagógico e lugar nos manuais pedagógicos para ensino de geometria. Um dos primeiros a dar aplicabilidade aos estudos piagetianos no ensino da Matemática e, em especial da Geometria, é Zoltan Dienes.

\section{Dienes e o ensino de Geometria para crianças}

Em 2007, é publicada a obra The legacy of Zoltan Dienes. Em seu Prefácio, o editor faz uma apresentação de Dienes, destacando:

Zoltan Paul Dienes (1916-) é considerado uma lenda viva no campo da educação matemática, por seu pioneiro trabalho e por sua atuação, que já conta mais de 50 anos de atividades. Tendo formação matemática na Inglaterra, interessou-se pela psicologia da aprendizagem na década de 1950, obtendo sua segunda graduação em Psicologia. 0s trabalhos desse autor, influenciados pelo estruturalismo e pela psicologia cognitiva trouxeram originalidade ao campo da educação matemática. Os livros Building up Mathematics (Dienes, 1960) e Thinking in Structures (Dienes \& Jeeves, 1965) influenciaram educadores matemáticos do mundo inteiro (Sriraman, 2007, p. i).

A biografia de Dienes é muito extensa; no entanto, para o foco deste estudo, interessa destacar que, nos anos 1960, através do Office Central De Librairie - OCDL, Zoltan Dienes publica a coleção First years in mathematics / Les premiers pas en mathématiques. Um dos volumes da coleção tem por título Exploration of space and practical measurement / Exploration de l'espace et pratique de la mesure. No Brasil, os textos de Dienes são editados no final da década de 1960. Em 1977, precisamente, sai a terceira edição, do volume III da coleção de Dienes, intitulado Exploração do espaço e prática da medição. Junto com Dienes, assina, como coautor, E. W. Golding.

Iniciando a obra, em sua Primeira Parte, o item “Ideias fundamentais” destaca:

A geometria é a exploração do espaço. Uma criança, desde seu nascimento, explora o espaço. Primeiramente o olha, depois o sonda com seus braços 
e pernas visando a descoberta, e enfim se desloca nele. É preciso um tempo bastante longo para desenvolver as ideias de perspectiva, de distância, de profundidade; noções como as de dentro e fora, diante e atrás, antes e depois, $e$ assim por diante. [...] As primeiras noções de geometria não têm nada a ver com a medida. Uma criança preocupa-se muito pouco com a distância exata dos objetos, de seus movimentos ou do ângulo sob o qual as coisas são vistas (Dienes; Golding, 1977, p.1, grifos nossos).

Mais adiante, os autores ponderam que é necessário tratar o ensino de geometria para crianças pelas noções de "dentro" e "fora”, "aberturas", "adiante" e "atrás" etc.: deverão essas noções ser "qualificadas em geometria de topológicas, que é preciso começar aqui” (Dienes; Golding, 1977, p. 2). Em seguida, os autores tratam do tema “Topologia”. Em linguajar fácil e simples, colocam ao leitor propostas para trabalho com topologia para crianças:

Podemos oferecer às crianças alguns jogos interessantes com as fronteiras. Suponhamos ter que lidar com um espaço de duas dimensões: um jardim e um pátio. Consideremo-lo tão grande que suas fronteiras não possam ser vistas em nenhuma direção e tracemos as fronteiras a nosso arbítrio. Por exemplo, disponhamos ao acaso, no chão, certo número de aros com diâmetros variados, cuidando para que não se toquem. Podemos colocar aros pequenos dentro de grandes. Depois dizemos às crianças que se separem como bem entenderem, algumas fora dos aros, outras no interior de um aro isolado, outras entre um aro pequeno e um grande. Perguntemos então, à classe, se é possivel, por exemplo, a Pedro ir visitar Francisca sem atravessar nenhuma "fronteira". Repetimos o exercício diversas vezes, nomeando crianças diferentes: às vezes será possível, outras vezes, não. [...] (Dienes; Golding, 1977, p. 3-4, grifo nosso).

Com atividades como essa, as crianças terão interesse nas propriedades topológicas do espaço, nas fronteiras, nas portas, nos espaços e nos domínios, sem atenção especial para a medida. Nessa etapa de aprendizagem, elas não estão ainda mentalmente preparadas para os desenhos geométricos de formato pequeno, realizados sobre uma folha de papel (Dienes; Golding, 1977, p.6). 


\section{Livros didáticos e o ensino de Geometria}

As propostas de Dienes repercutem nos novos livros didáticos. No Brasil, um dos primeiros textos publicados para as séries iniciais, sob a égide da Matemática Moderna, é a coleção de autoria de Manhúcia Perelberg Liberman, Anna Franchi e Lucília Bechara. Trata-se do Curso Moderno de Matemática para escola elementar, escrito em cinco volumes, com o primeiro volume lançado em 1966/67 (França, 2007, p. 76).

A pesquisadora Lúcia Villela, em sua tese de doutoramento, considera que o trabalho dessas autoras "constituiu a dimensão mais visível da entrada em cena das educadoras matemáticas" (Villela, 2009, p.17). Explica-se: a elaboração de obras didáticas para o ensino de primeiras letras, em especial aquelas de Matemática, até meados da década de 1960, não tem autoria de professores formados em cursos de Licenciatura em Matemática. Liberman, Franchi e Bechara têm essa formação.

Para além do pioneirismo, os livros didáticos dessas autoras ganham importância para a análise, na medida em que constituem verdadeiros best-sellers do ponto de vista de quantidade de exemplares vendidos ao tempo do $M^{M} M^{6}$.

A razão do sucesso editorial da Coleção aponta para vários componentes: pioneirismo, contexto do MMM, amparo da maior editora de livros didáticos (Cia. Nacional) presente em todo o País e, ainda, o envolvimento das autoras em centros de estudos, em cursos e palestras para professores sobre Matemática Moderna, participação nas equipes de elaboração de propostas curriculares, dentre outras ações (Villela, 2009, p.140). Esses elementos todos contribuem para explicar o sucesso de uma coleção para o ensino primário completamente diferente das obras que circulavam até então pelas escolas.

A introdução dessa coleção didática constituirá ingrediente importante para modificações na cultura escolar, nos termos em que esse conceito é compreendido pelo historiador Dominique Julia (2001, p.10, grifos nossos):

Um conjunto de normas que definem conhecimentos a ensinar e condutas a inculcar, e um conjunto de práticas que permitem a transmissão desses conhecimentos e a incorporação desses comportamentos.

6. Villela (2009, p.135), em estudo muito detalhado nos arquivos da antiga Cia. Editora Nacional, mostra que, no período de fevereiro de 1967 a maio de 1974, foram comercializados 2.588.611 exemplares da Coleção.
Para explicar sinteticamente, pode-se dizer que, pelo menos em termos de normas para o trabalho pedagógico, altera-se substantivamente a orga- 
nização dos conteúdos escolares matemáticos a serem ensinados para as crianças.

A análise interna das obras didáticas mostra que, no segundo volume dessa série pioneira de Matemática Moderna para o ensino primário, destinado ao segundo semestre do primeiro ano escolar, estão presentes os seguintes conteúdos: adição com três ou mais números; leitura e escrita dos números de 20 a 99; multiplicação e divisão; fatos fundamentais da multiplicação e da divisão com produto igual ou inferior a 20; conceito de metade, dobro, terça parte, triplo, quarta parte, quádruplo; e reconhecimento de forma. Neste último tema, as autoras incluem, nas três últimas páginas do livro, exercícios solicitando aos alunos, a partir de gama variada de desenhos, que reconheçam formas que pareçam o cubo, a esfera e o cilindro. De outra parte, no terceiro volume da coleção, destinado ao segundo ano escolar, os conteúdos presentes na obra, de acordo com a escrita das próprias autoras na "Nota Introdutória", são: estudo dos números maiores que 100 e menores que 1000; adição com reserva; subtração com recurso; fatos fundamentais de produto até 81; multiplicação com números maiores que 10; divisão não exata; medida de comprimento, tempo, massa; noções de geometria; noções de frações. Na observação de como se desenvolvem os conteúdos relativos às noções de geometria, verificam-se exercícios como "Cubra com verde as curvas fechadas e com azul as curvas abertas", tarefas com "curvas fechadas simples e curvas fechadas não simples". Tais atividades de ensino surgem como temas inéditos até então, dentro da geometria para crianças.

Desde essa Coleção, os livros didáticos passarão, em tempos do MMM, a incluir temas da Topologia, um novo conhecimento elementar da geometria para crianças.

\section{A ontogênese segue a filogênese?}

Psicogênese e história das ciências, escrito por Jean Piaget e Rolando Garcia, é o último livro em que surge o nome do famoso epistemólogo suíço como autor. Publicada em 1983, a obra é finalizada um pouco antes da morte de Piaget, ocorrida em 1980 (Keller, 2001).

A Psicogênese representa um enorme esforço teórico de mostrar em que medida a construção do conhecimento pelo indivíduo - a aprendizagem - segue a ordem da produção histórica do saber. Dito de outro modo: como a ontogênese segue a filogênese. Para o que interessa a este texto, destaquem-se o Capítulo III - "O desenvolvimento histórico da Geometria" - e o seguinte, Capítulo IV: "A psicogênese das estruturas geométricas". No primeiro, os autores mostram o trajeto histórico que teve 
como etapas a geometria euclidiana, a geometria projetiva e, por fim, a topologia. Em sua conclusão, o texto sintetiza:

A geometria começa, com Euclides, por um período durante o qual se estuda as propriedades das figuras e dos corpos geométricos enquanto relações internas entre elementos destas figuras e destes corpos. Não se toma em consideração o espaço enquanto tal, nem, por consequência, as transformações das figuras no interior e um espaço que as compreenderia todas. Chamaremos a esta fase intrafigural, utilizando uma expressão já utilizada em psicologia genética para dar conta do desenvolvimento das noções geométricas na criança. Vem em seguida uma etapa caracterizada por um estabelecimento de relação das figuras entre elas, cuja manifestação específica é a procura de transformações, ligando figuras segundo múltiplas formas de correspondências, mas sem chegar a subordinação das transformações às estruturas de conjunto. É o período durante o qual a geometria dominante é a geometria projetiva. Chamaremos esta fase interfigural. Em seguida começa uma terceira etapa, que chamaremos transfigural, caracterizada pela proeminência das estruturas. A expressão mais caracterizada desta etapa é o Programa Erlangen, de Félix Klein. Estas três etapas, bem delimitadas na história da geometria, testemunham a evolução no processo da conceitualização das noções geométricas (Piaget; Garcia, 1987, p. 110, grifos nossos).

Na própria síntese final do Capítulo III, os autores já antecipam os resultados a serem descritos no capítulo seguinte, quanto ao estudo da marcha da aprendizagem da geometria pelas crianças:

0 ponto da partida da análise que apresentaremos aqui é o conjunto dos conceitos desenvolvidos pela escola de Genebra através das investigações em psicologia genética. A fecundidade deste aparelho conceitual, aplicado à história da ciência, mostra não apenas a convergência dos estudos histórico-críticos e psicogenéticos, sustentada desde há muitos anos por um dos autores da presente obra, mas também a possivel interação efetiva no processo de elaboração de cada um dos temas (Piaget; Garcia, 1987, p. 110) 
Em suma, a convergência mencionada dirá respeito ao paralelo entre a ontogênese e a filogênese, no que toca à geometria. A marcha da aprendizagem da geometria pelas crianças segue a evolução histórica da própria geometria. 0 processo de aprendizagem vai do intrafigural ao transfigural, passando pelo interfigural...

Um dos pontos altos do texto Préhistoire de la géométrie: le problème des sources, de Olivier Keller, é justamente mostrar essa contradição dos trabalhos de Piaget. Keller ressalta que o livro Psicogênese e história das ciências contradiz, de maneira evidente, duas das obras publicadas por Piaget anteriormente: La représentation de l'espace chez l'enfant, publicada em 1947, e La géométrie spontanée de l'enfant, publicada no ano seguinte. Diz Keller (2001, p. 24): “Em 1947-48, Piaget pensava que a ordem genética e a ordem histórica eram inversas; em 1980, as mesmas experiências o conduzem a uma conclusão oposta”.

\section{A geometria de sempre: a geometria euclidiana}

Mesmo em meio a um contexto revolucionário de propostas de mudança da Matemática escolar, o MMM encontra o cotidiano pronto para incorporar novos elementos da Geometria, sem que efetivamente seja abandonada a geometria euclidiana. Por entre as páginas e páginas dos livros didáticos que enfatizam os elementos da teoria dos conjuntos, logo virá a Geometria com os primeiros itens da Topologia. Mas esses elementos mesclam-se, servem como rápida introdução para o estudo das figuras geométricas euclidianas. Em alguma medida, é possível dizer que há certa similaridade entre a incorporação da Topologia e os elementos do pré-cálculo, para o ensino de aritmética. No caso destes últimos, os livros didáticos passam a incluir, antes do trabalho com o sistema de numeração, com as operações aritméticas, uma série de atividades preparatórias. Seriação e ordenação são exemplos de atividades a serem desenvolvidas pelos alunos, que levariam ao conceito de número. No caso da Geometria para crianças, os rudimentos de Topologia passam a ser vistos, ao que tudo indica, como uma pré-geometria. E, neste caso, não há, nas obras didáticas, uma linha de continuidade entre elementos topológicos, projetivos e euclidianos. Apresentados alguns rudimentos de Topologia, passa-se, a seguir, à geometria euclidiana.

Ao tempo do MMM, tenta-se mostrar a ordem inversa de aprendizagem da Geometria em relação àquela histórica. Depois, retorna-se ao ponto inicial do paralelismo entre a ontogênese e filogênese, já com o Movimento exaurido. À parte essas idas e vindas teóricas, a cultura escolar, abalada pelas incisivas investidas do modernismo, 
retoma a geometria euclidiana como forma elementar de ensino da Geometria. Figuras geométricas e suas propriedades representam o saber geométrico que as crianças devem aprender na escola hoje.

É possível dizer, com o exemplo analisado, que a redefinição do elementar, dos rudimentos que devem ser ensinados para as crianças iniciarem sua incursão aos saberes científicos, não envolve tão somente os aspectos epistemológicos da pesquisa. Ressalte-se: não há uma linha de transmissão direta entre eles e as produções pedagógicas. Está presente o fenômeno da apropriação. As novas propostas e sua penetração nas salas de aula dependem de uma cultura estabelecida - a chamada cultura escolar. Essa cultura, por vezes, mesmo na contramão da pesquisa, faz o que o debate teórico paradoxalmente, às vezes, tende a confirmar... 


\section{Referências bibliográficas}

BORGES, A. C. Geometria pratica popular. Rio de Janeiro: Livraria Francisco Alves. 1882 (1878, 1a. edição).

CARVALHO, M. M. C. Pedagogia da Escola Nova, produção da natureza infantil e controle doutrinário da escola. In: FREITAS, M. C.; KULMANN JR, M. (Org.) Os intelectuais na história da infância. São Paulo: Cortez, 2002.

CHARTIER, R. A história cultural - entre práticas e representações. Lisboa: Difel; Rio de Janeiro: Bertrand Brasil, 1990.

DIENES, Z. P.; GOLDING, E. W. Exploração do espaço e prática da medição. São Paulo: EPU, 1977.

FRANÇA, D. M. A. A produção oficial do Movimento da Matemática Moderna para o ensino primário do Estado de São Paulo (1960-1980). Dissertação (Mestrado em Educação Matemática) - Pontifícia Universidade Católica de São Paulo - PUC-SP, São Paulo, 2007.

FREIRE, O. Primeiras noções de Geometria pratica. Rio de Janeiro: Francisco Alves, 1907.

GONDRA, J. G.; SAMPAIO, T. Ciência pela força? Dr. Abílio Cesar Borges e a propaganda contra o emprego da palmatória e outros meios aviltantes no ensino da mocidade (1856-1876). Acta Scientiarum. Education, Maringá, PR, v. 32, n. 1, p. 75-82, 2010.

JULIA, D. A cultura escolar como objeto histórico. Revista Brasileira de História da Educação, Campinas, SP, n. 1, jan./jun. 2001, SBHE; Autores Associados.

KELLER, O. Préhistoire de la géométrie: le problème des sources. Conférence donnée pour Olivier Keller à l'IREM de la Réunion em août 2001. Disponível em: reunion.iufm. $\mathrm{fr} /$ Recherche/irem/IMG/pdf/Keller_prehistoire_geometrie.pdf. Acesso em: 22 jun. 2011.

LEME DA SILVA, M. C. A prática da geometria prática no ensino primário: subsídios para uma história disciplinar. In: REUNIÃO ANUAL DA ANPED, 33., 2010, Caxambu. Anais... Caxambu, MG, 2010.

LIBERMAN, M. P.; FRANCHI, A.; BECHARA, L. Curso moderno de Matemática para a Escola Elementar. São Paulo: Companhia Editora Nacional, 1968.

LOBO, J. TH. S. Primeira Arithmetica para meninos. Porto Alegre: Livraria do Globo, 1935 .

PAIS, L. C. Traços históricos do ensino da aritmética nas últimas décadas do século XIX: livros didáticos escritos por José Theodoro de Souza Lobo. Revista Brasileira de História da Matemática, v.10, n. 20. (no prelo). 
PFROMM NETO, S. O livro na educação. Rio de Janeiro: Primor; INL, 1974.

PIAGET, J.; GARCIA, R. Psicogénese e história das ciências. Lisboa: Dom Quixote, 1987.

PIAGET, J.; INHELDER, B. A representação do espaço na criança. Porto Alegre: Artes Médicas, 1993.

RAZZINI, M. P. G. Livro didático e expansão escolar em São Paulo (1889-1930). Língua Escrita, n. 1, jan./abr. 2007.

SRIRAMAN, B. (Ed.) Editorial: The legacy of Zoltan Paulo Dienes. The Montana Council of Teachers of Mathematics. Monograph 2, p. i-ii, 2007.

VALENTE, W. R. Uma história da matemática escolar no Brasil, 1730-1930. São Paulo: Annablume; FAPESP, 2007.

Recebido em 30 de novembro de 2011 e aprovado em 12 de julho de 2012. 